\title{
GSM Based Design and Development of Smart Energy Meter Using EEPROM, LCD, and Microcontroller
}

\author{
${ }^{1}$ Tukur Gupta, ${ }^{2}$ Vaibhav Karnail, ${ }^{3}$ Parth Pandey, ${ }^{4}$ Gaurav Verma \\ Department of Electronics \& Communication Engineering, \\ ${ }^{1}$ Ajay Kumar Garg Engineering College, Noida (Ghaziabad), India. \\ ${ }^{2,3}$ G. B. Pant University of Agriculture and Technology, Pantnagar (Uttarakhand), India. \\ ${ }^{4}$ Jaypee Institute of Information Technology, A-10, Sector-62, Noida (U.P.), India. \\ Email: ${ }^{1}$ tukur306@gmail.com, ${ }^{2}$ parthpandey5494@gmail.com, ${ }^{3}$ vaibhavkarnail1997@gmail.com, \\ ${ }^{4}$ gaurav.iitkg@gmail.com
}

\begin{abstract}
Traditionally electricity meter reading is done manually by a human operator who has to visit each house to record the reading. It requires huge number of human operators and long working hours to achieve complete area data reading and billing. With the rapid advancements in our present time, everything in our daily life is developing accordingly, and energy meters are no exception to this phenomenon. In our work we have discussed about smart energy meter where in there is a provision to give an alarm sound to the consumer before the whole amount gets finished. The energy meter also provides the utility company and the customer with regular status of the meter on predefined interval by means of an SMS and LCD Display. This technology mainly saves the utility providers from the expense of periodic trips to each physical location to read the meter. STM32F100RBT6B microcontroller unit has been used to continuously monitor and record the energy meter reading using External EEPROM and GSM technology. The software work is done using CooCox CoIDE.
\end{abstract}

Keywords: SMS, STM32F100RBT6B, EEPROM, GSM Technology, CooCox CoIDE.

\section{INTRODUCTION}

The technology of electrical metering instrument has travelled a long journey from how it was 100 years ago. From the heavy and bulky meters with heavy magnets and coils, there have been many improvements that have resulted in reduction of size \& weight. Resolution and accuracy of the meter have seen substantial betterment over the years. Introduction of the digital meter in the later part of last century has completely changed the way electrical parameters are measured. Today, the energy consumption and energy distribution is a big subject for discussion due to the large difference in amount of energy produced and consumed. As a result, so many problems are being faced by energy consumers due to increased frequency of power failures and an important reason for power cuts is the limitless consumption of energy by rich people. Thus, to minimize the power cuts and to distribute the energy equally to all areas, some restriction should be made on the power consumption of every individual. Hence, the need has come to think regarding this issue and a solution has to be emerged out. In this work, the Microcontroller unit is designed with STM32 VL Discovery Board based on STM32F100RBT6B controller. The Microcontroller works according to the program written in it. The idea is that the microcontroller will be placed in the device to calculate power and control other functions. Some features and benefits offered by this system are -

- Allows user to choose an option for electricity billing system.

- Smart automated processes instead of manual work.

- Minimizes the human errors.

- User can get precise information of his consumption.

- Clear \& accurate billing. 
- Customer can buy credit anytime in the month.

- Installation and operation is easy.

\section{LITERATURE SURVEY}

Md. Manirul Islam et al. present measurement of energy, remote monitoring, preparing of bill and billing system [1]. Whole system is controlled by low cost ATMEGA8L microcontroller. Voltage and current is sampled by it. Then data is processed to calculate power in that instant. Then total energy consumed by the consumer is stored charge of energy is calculated using tariff. LCD display is used to show total energy consumption, power factor and cost etc. This system is more accurate, stable, reliable, and cost effective. Jubi.K et al. aim to eliminate the queue at the electricity billing counters and to cut the power supply automatically, if the bill is not paid [2]. This project proposes a system that will lead to the reduction in power thefts and other illegal activities and thus leading to the reduction in loss in power and revenue. Md. Mejbaul Haque et al. demonstrate a single phase digital prepaid energy meter using two microcontrollers and a single phase energy meter IC [3]. Output pulses of the energy meter chip and counter of microcontroller (ATmega32) are used for energy calculation. A microcontroller (ATtiny13) is used to write no. of units recharged in smart card. $M$. Jebashathini et al. presents energy monitoring and controlling by prepaid system [4]. This work helps the consumers for betterment of energy management and it is used in the distribution system for economic liability of the Electrical Boards. Noman Mehmood et al. develop a system using which real time values of the energy consumption are calculated and can be sent to the nearest electric meter billing and controlling station [5]. For this analog electric meter is interfaced with the digital circuitry. Thus real- time billing is made possible \& reading is displayed using Liquid Crystal Display (LCD). Sapna Ganurkar et al. demonstrate an idea of a Prepaid energy meter using an AT89S52 [6]. This work provides a cost efficient method of electricity billing. Sudarshan K. Valluru presents the design and assembly of smart card prepaid electricity meter system, which allows the consumer to buy required amount of energy and also gives information about their credit balance [7]. A system has been developed with the digital and information technology and proven to include many advantages such as stability, reliability, tamper resistance, low cost, and easy maintenance. In this paper, a prepaid metering (PPM) system has been introduced. N A Rai et al. discuss the GSM Based prepaid and post paid Energy meter [8]. This Energy Meter has many capabilities. Monitoring and controlling of meter can be done remotely. Meter Reading is done automatically. Theft Detection is made possible. Message alerts are sent to the customer. Mohammed Imran Khan et al. present the "Prepaid and Post paid Automatic Power Meter Reading System". Many advanced study results in computer technology and communication technology are absorbed in this work [9]. Using this system, task of meter reading is accomplished at management department of residential area. The consumption of power can be monitored by the department of energy resources management which helps in improving the utility of power.

\section{TECHNICAL SPECIFICATION}

\section{A.) Hardware description:}

1.) ARM Cortex M3 (STM32F100RBT6B):

ARM is a 32-bit reduced instruction set computer (RISC) instruction set architecture (ISA) developed by ARM Holdings. It was previously named the Acorn RISC Machine followed by the Advanced RISC Machine. This is the most widely used 32-bit instruction set architecture. 2.) Opto-coupler IC 4N35:

4N35 is an optocoupler integrated circuit in which an infrared emitter diode drives a phototransistor. They are also known as optoisolators since they separate two circuits optically. 
These are used to couple two circuits without any ohmic contact. They allow one of the circuits to switch another one while they are completely separate.

3.) LCD Module:

LCD screen is an electronic display module and find a wide range of applications. A 16x2 LCD display is very basic module and is very commonly used in various devices and circuits.

4.) GSM Module:

GSM Module is used in this project to make communication between the customer and the meter.

5.) RFID Module:

RFID Module is used in this project to recharge the smart card in case of prepaid meter with the desired amount of units. An RFID reader is a device which is used to communicate with RFID tags by receiving and transmitting signals. Radio waves are used by these devices for wireless communication. RFID tag is applied to products, individuals or animals for the purpose of identification and tracking.

6.) RFID Tags:

There are different frequencies on which different RFID tags work. Here RFID tags with low frequency i.e. $125 \mathrm{kHz}$ have been used. This low frequency RFID card is used in a variety of applications such as ticketing, security access control and prepayment devices and many more. 7.) EEPROM IC AT24C08:

The EEPROM used in this project is 24C08 type. It uses I2C protocol to communicate with Host controller (STM32F100RB in this case). The AT24C08 provides 8192 bits of serial electrically erasable and programmable read-only memory (EEPROM) organized as 1024 words of 8 bits each.

8.) ULN2003 Driver IC:

ULN2003 is a high voltage and high current Darlington array IC [29]. It contains seven open collector darlington pairs with common emitters. ULN2003 belongs to the family of ULN200X series of ICs. Different versions of this family interface to different logic families. These ICs are used when driving a wide range of loads and are used as relay drivers, display drivers, line drivers etc.

9.) Buzzer:

A buzzer is an audio signalling device which may be mechanical, electromechanical, or piezoelectric. Typical uses of buzzers and beepers include alarm devices, timers and confirmation of user input. In our system, we have used electromechanical buzzer.

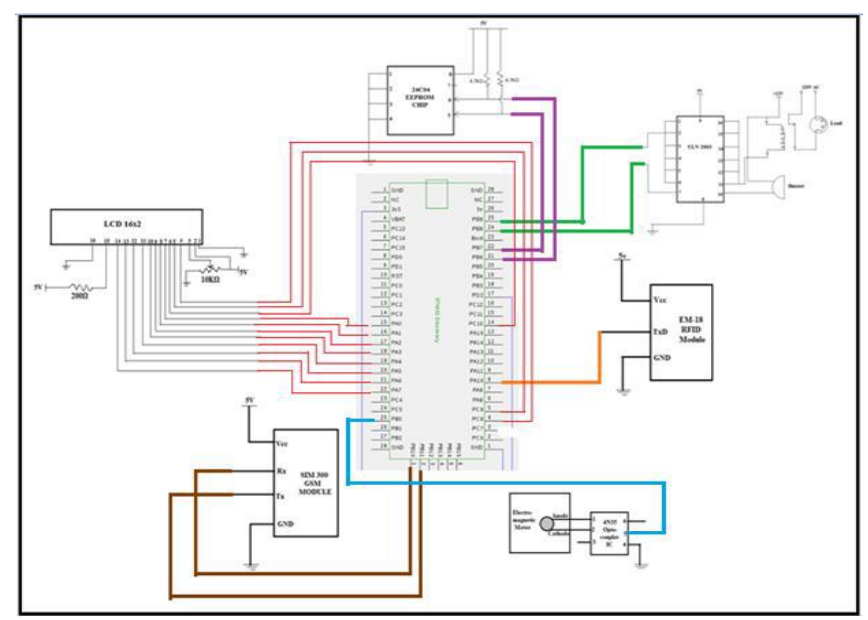

Fig1: Complete Circuit Diagram 


\section{B.) Software Description:}

1.) CooCox CoIDE:

CooCox is a company that provides free software that can match the software of the giants in the business. The software is split into modules and two of the major ones are:

\section{-CooCox CoIDE}

\section{- CooCox CoFlash}

CooCox CoIDE is a new, free and highly-integrated software development environment for ARM based microcontrollers. This includes all the tools necessary to develop high-quality software solutions in a timely and cost effective manner. It has a built-in debugger. CoIDE consists of a component-based network platform and an Eclipse-based development environment. Using component-based network platform can quickly obtain resources can be quickly obtained to build applications, share your resources and exchange ideas. The Eclipse based development environment provides many features for code editing, code browsing, compiling, linking, debugging, project management, etc.

\section{WORKING}

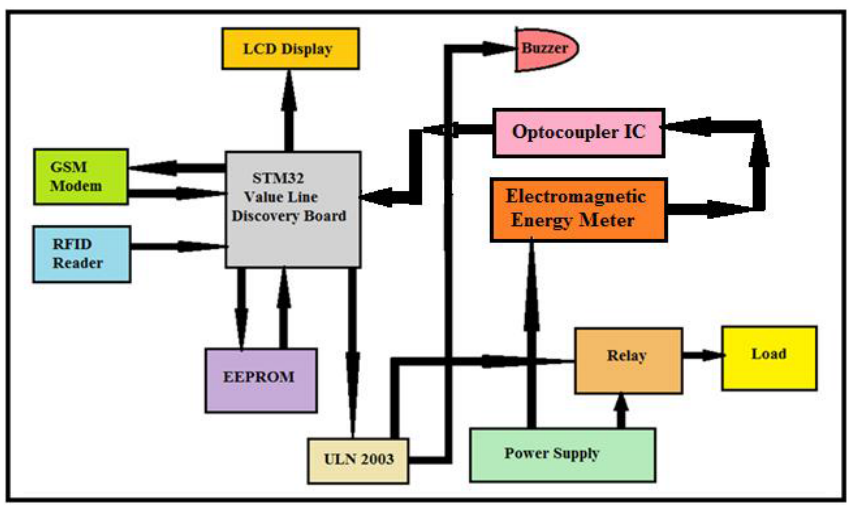

Fig2: Proposed System Block Diagram

The working of this smart system starts when the user tries to consume the power i.e. when he switches on any of the electrical appliances in his house. When these electrical appliances are switched on, they consume some power. The meter fixed outside the house will display the number of consumed units. The main concept of the smart energy meter lies in buying the energy card from the electrical department, inserting it into the energy card reader fixed in the house; consume it according to the number of units available in the card. The product that we developed uses STM32F100RB Microcontroller to control all the functions. We have used EEPROM to store the reading at regular intervals. The system will be in OFF state until and unless the user recharges the Smart Card. Here the system is connected to a load. Now, as the power consumption increases the rate of pulses from the output pin 5 of the Optocoupler IC 4N35 increases and the microcontroller counts these pulses, when these pulses reaches a specific number which depends on the meter constant of energy meter. For the sake of convenience we have considered one Led Blink equal to one unit consumed. Thus one unit is decremented from the total units with each blink and these values are displayed on 16X2 LCD. System will give a continuous beep sound as the unit value goes below 10 units. When the number of units becomes zero the relay operates and interrupts supply using relay. At this instant the user has to recharge RFID tag based card and has to recharge by inserting the recharge card in the slot provided in RFID tag reader. Here recharging means loading a new unit's value to the recharge card. After recharge, the user has to swipe the recharge card over 
the RFID Reader, if the recharge card is valid then a message is displayed as Recharge successful and the system automatically turns ON. If it is Invalid then a message is displayed as Invalid card and gives a continuous beep sound. Microcontroller regularly prompts GSM modem after regularly intervals of time to check if there is a message. It executes commands according to the message and then deletes it. AT Commands are sent to the GSM modem by microcontroller for reading and writing messages. Phone number of service provider is already stored in microcontroller to compare with sender of command SMS (power cut off or power resume), no unauthorized person can operate the power switch.

\section{RESULTS AND DISCUSSION}

As soon as the meter is powered ON, the following message is displayed on the LCD screen as shown in Fig.3.

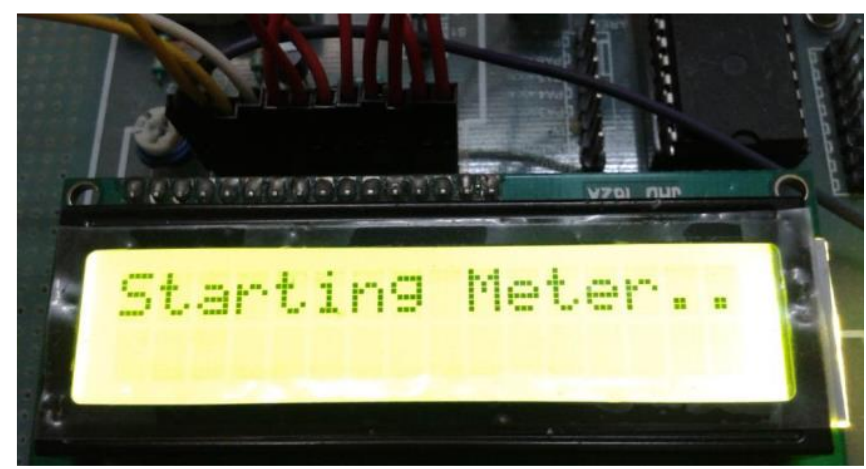

Fig3: Welcome Screen of proposed System

Microcontroller checks whether the No. of Units Left is less than 10. If yes then the GSM Modem sends SMS to the customer as shown below as shown in Fig.4.

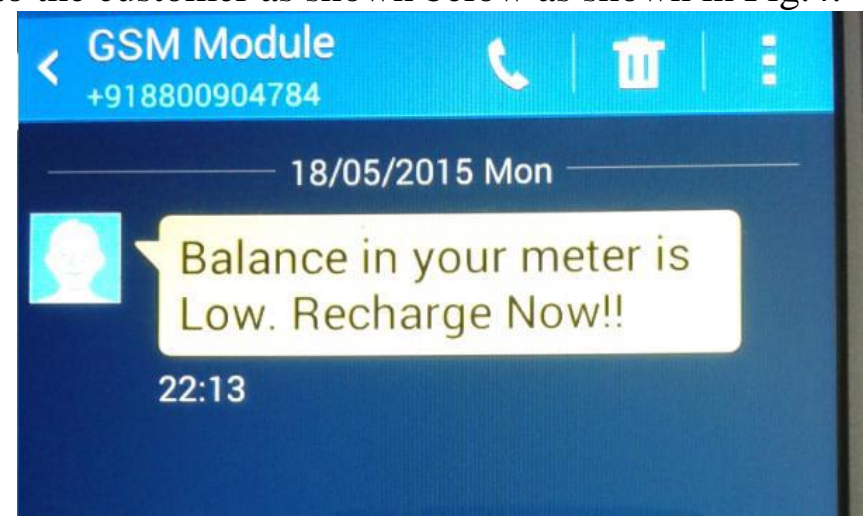

Fig4: SMS obtained by the customer when meter balance is less than 10 units

Microcontroller checks whether the No. of Units Left is less than 10. If yes then the following message is displayed on the LCD screen as shown in Fig. 5. 


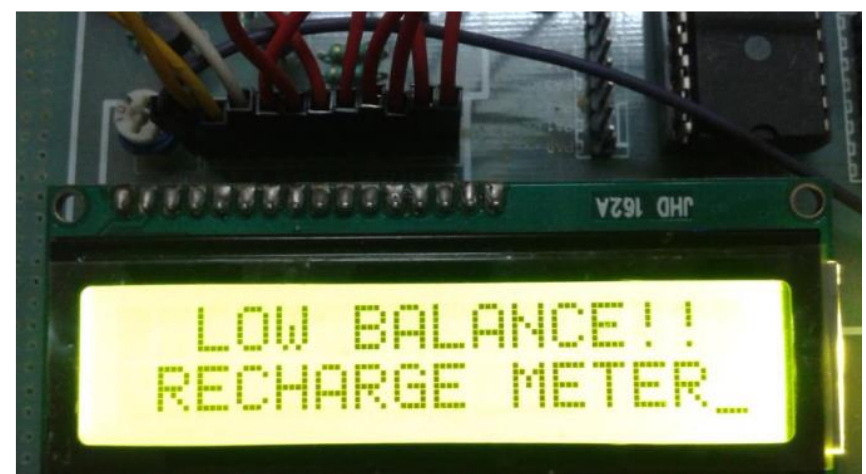

Fig5: Message displayed on LCD screen when meter balance is less than 10 units

The customer will swipe the Smartcard (RFID Tag) over the RFID Reader. Microcontroller will check if the card is valid or not. If it is invalid, the following message will be displayed on LCD Screen as shown in Fig.6.

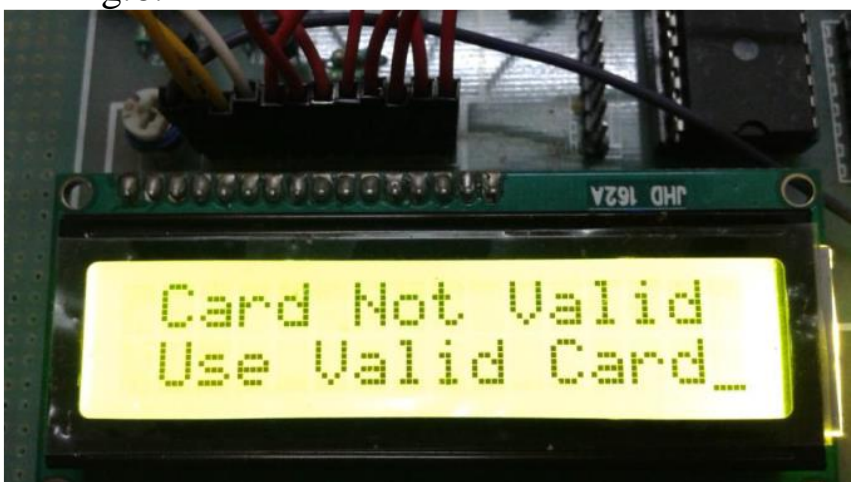

Fig6: Message displayed on LCD screen if card swiped is not valid

If the Smartcard is valid, the following message will get displayed on the LCD Screen as shown in Fig. 7. The meter will get recharged.

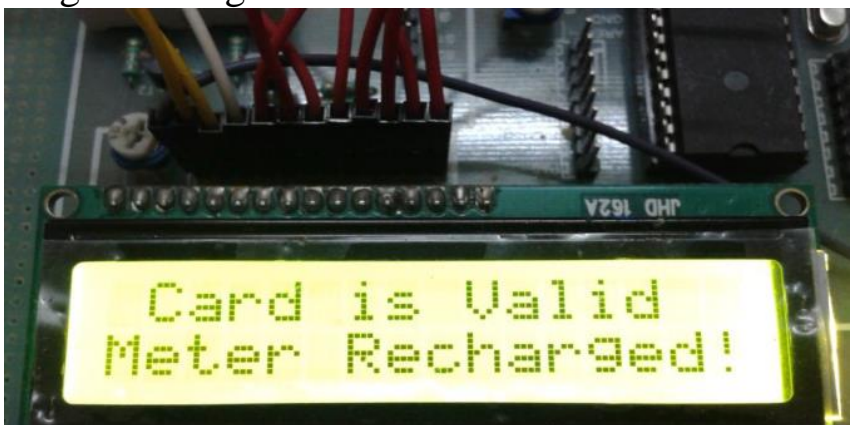

Fig7: Message displayed on LCD screen if card swiped is valid

Units stored in the microcontroller will be updated by 200 units and following message will be displayed on LCD Screen as shown in Fig. 8. 


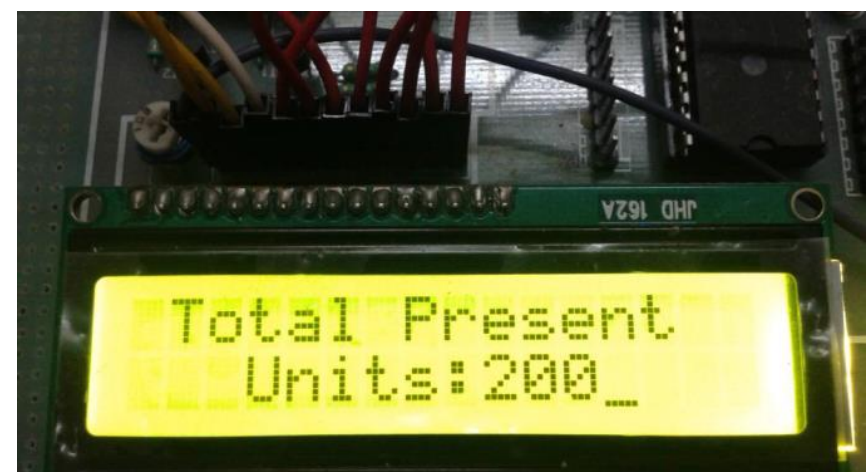

Fig8: Message displayed on LCD screen after meter gets recharged.

Normally, the microcontroller will obtain the pulses from the Electromagnetic Energy Meter using the optocoupler IC and will calculate the consumed Energy depending upon the Load. The LCD screen will display the current time (in terms of hours, minutes and seconds), Consumed Energy (in terms of KWh) and remaining units (Bal).

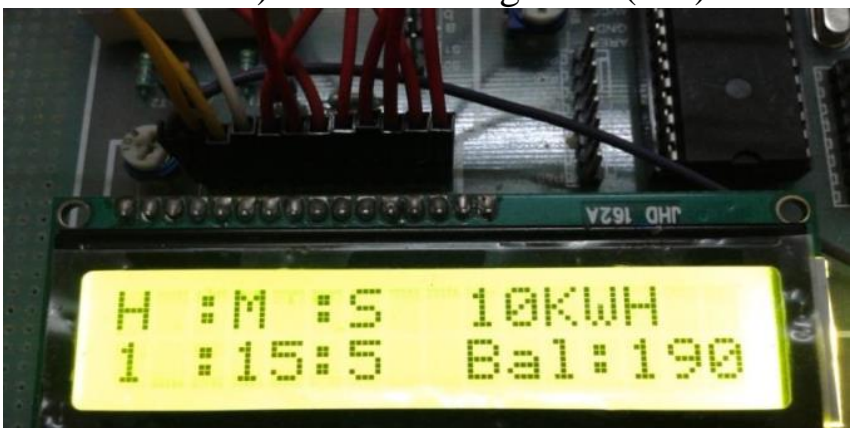

Fig9: Information displayed on LCD screen all the time

The following SMS is sent by the microcontroller at regular intervals to the customer as shown in Fig. 10.

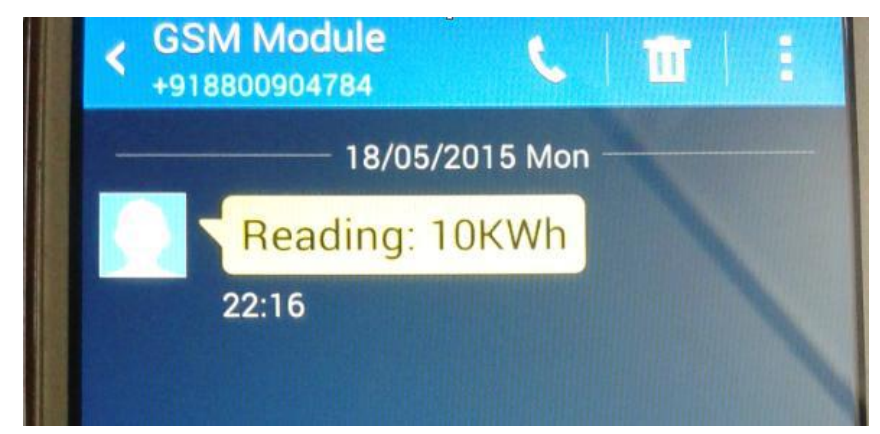

Fig10: SMS received by the customer for Current Reading

The following SMS is sent by the microcontroller at regular intervals to the customer as shown in Fig. 11.

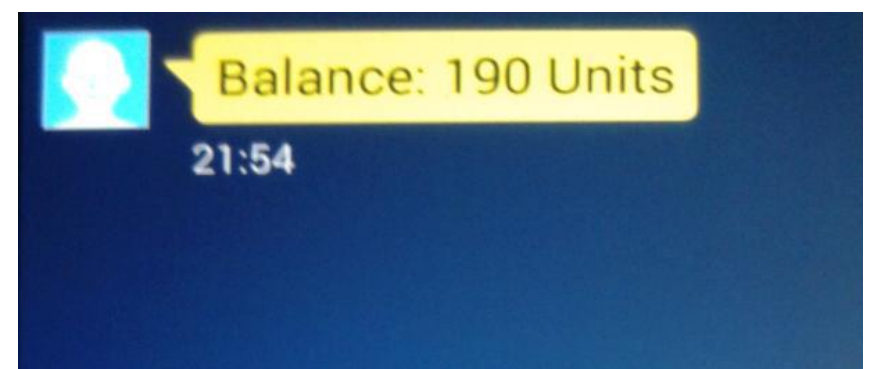

Fig 11: SMS received by the customer for remaining balance information 
In case of Postpaid meter system, the following SMS will be received by the customer as shown in Fig. 12.

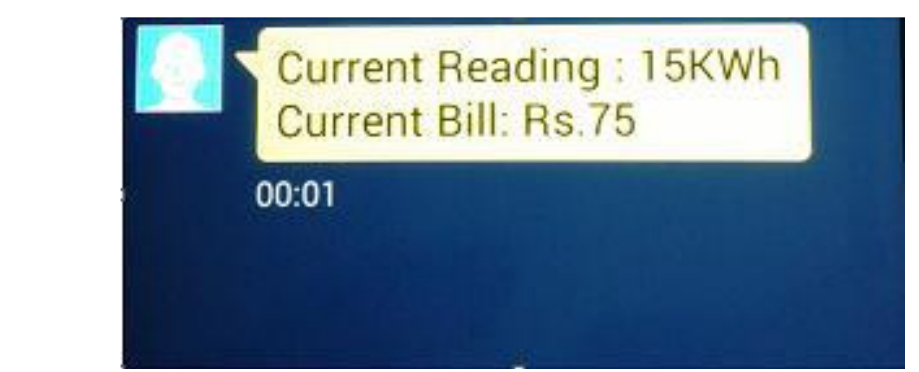

Fig12: SMS received by the customer for Current Reading and Bill

(Postpaid System)

\section{CONCLUSION}

In "Smart Energy Meter", energy consumption calculation based on the counting of pulses is designed and implemented using STM32F100RB MCU in embedded system domain. An LCD is provided to display the number of units remaining, so controlled usage of energy is possible and this system eliminates burden of electricity billing and saves money and time for electricity department and consumers respectively. The proposed energy meter demonstrates \& implements new concept of power meter reading system. Presence of every module has been reasoned out and placed carefully thus contributing to the best working of the unit. Secondly, using highly advanced IC's and with the help of growing technology of GSM, the project has been successfully implemented. For long distance transmission, GSM telecommunication shows excellent performance at any conditions. This system helps in efficiently using power $\&$ reduces the unnecessary wastage of power. More over instead of recharging the chip, the readily available RFID or recharge cards (smart cards) used in cell phones have been introduced. Using these mechanisms, consumers can recharge their meters at their convenience and making the system much more user friendly.

\section{FUTURE SCOPE}

In future we can design a mobile app to obtain the energy usage when desired using the Bluetooth Module. Water \& cooking gas distribution system can also be meterized in the same manner. We can also bundle up the readings of all the three meters and then send it via SMS using the same embedded system. Also, the mode of recharging the smart card can be improved. Furthermore, same idea can be extended to three phase systems also by using the three phase IC.

\section{REFERENCES}

[1] Md. M Islam, M Ahmed, Md. A Islam, A F Mitul, M F Malek, and M A Rashid, "Electronic Energy Meter with Remote Monitoring and Billing System", 7th International Conference on Electrical and Computer Engineering, 2012, pp.240-243.

[2] Jubi.k and M.John, "Prepaid Energy Meter with GSM Technology", AIJRSTEM, vol.13, pp.195-198, 2013.

[3] Md. M Haque, Md. K Hossain, Md. M Ali, and Md. R Sheikh, "Microcontroller Based Single Phase Digital Prepaid Energy Meter for Improved Metering and Billing System”, IJPEDS, vol.1, pp.139-147, 2011. [4] M.Jebashanthini , A.Sweety, R.Rini, and A.Alfred Kirubaraj, "Advanced Prepaid Energy Metering System Using GSM”, Indian Streams Research Journal, ISSN:-2230-7850.

[5] Noman Mehmood, Zain Anwar Ali, Ali Akbar Sidiqui, M.Asif, and Sarwar Wasi, "Electronic Meter Reader \& Data Base Management System”, 6th IEEE Joint International, vol.1, pp.68-71, 2011.

[6] S.Ganurkar and P.Gour, "Prepaid Energy Meter for Billing System Using Microcontroller and Recharge Card”, IJCEM, Vol.1, Issue 1, pp.12-18, 2014. 


\section{Gyancity Journal of Electronics and Computer Science, \\ Vol.2, No.1, pp.49-57, March 2017 \\ ISSN: 2446-2918 DOI: 10.21058/gjecs.2017.21006}

[7] S.K.Valluru, "Design and Assemble of Low Cost Prepaid Smart Card Energy Meter-A Novel Design", IJEEI, Vol.6, No.1, pp.65-72, 2014.

[8] N A Rai and R Sathyanarayana, "GSM Based Energy Meter with Prepaid/Postpaid Facility", IJVES, Vol.5, pp.1083-1088, 2014.

[9] M.I. Khan and J.Chaurasia, "Prepaid and Postpaid Automatic Power Meter Reading System”, Ultra Engineer, Vol.1, pp.89-94, 2012.

[10] S.Kar, S.Dutta, A.Sarkar, and S.Das, "Rechargeable Prepaid Energy Meter Based on SMS Technology", IJEIT, Vol.3, Issue 10, pp.142-144, 2014.

[11] Ashna.K and S N George, "GSM Based Automatic Energy Meter Reading System with Instant Billing", International Multi-Conference on Automation, Computing, Communication, Control and Compressed Sensing (iMac4s), 2013, pp.65-72.

[12] C Landi, P Merola, and G Ianniello, "ARM-Based Energy Management System using Smart Meter and Web Server", Instrumentation and Measurement Technology Conference (I2MTC), 2011, pp.1-5.

[13] S K Ellenki, S Reddy G, and Srikanth Ch., "An Advanced Smart Energy Metering System for Developing Countries", IJSRE, Vol.2, Issue 1, pp.242-258, 2014.

[14] R G Sarangle, U P Khot, and J Modi, "GSM Based Power Meter Reading and Control System", IJARCET, Vol.1, Issue 4, pp.273-279, 2012.

[15] N Mohammad, A Barua, and Md. A Arafat, "A Smart Prepaid Energy Metering System to Control Electricity Theft", International Conference on Power, Energy and Control, 2013, pp.562-565.

[16] C Landi, G D Prete, D Gallo, and M Luiso, "The Use of Real Time Systems for Smart Power Systems", 2nd IEEE ENERGYCON Conference and Exhibition, 2012, pp.884-889.

[17] A Fakharuddin, R Abdullah, A N Abdalla, and Md.R B Ahmad, "Modern Control of Electrical Consumption System Using Wireless Reader Designed Algorithm", International Conference on Information, Networking and Automation, 2010, pp.184- 187.

[18] T Kamalesh and M V Chary, "Post-paid Wireless Meter Reading System for Automatic Power Controlling and Consumption Billing Applications", IJSETR, Vol.2, Issue 9, pp. 1673-1677, 2013.

[19] Boyina, S Rao, B. Gnanasekaranathan, M. Raguram, S. Pravinkumar, and P. Kamalesh "Domestic Prepaid Energy Distribution System for Saving of Power Consumption" IJAET, Vol.3, Issue 2, pp. 26-29, 2012.

[20] H G Rhodney Tan, C H Lee, and V K Mok, "Automatic Power Meter Reading System Using GSM Network", 8th International Power Engineering Conference, 2007, pp. 465- 469.

[21] Gaurav Verma, Amit Yadav, Sanjay Sahai, Utkarsh Srivastava, Shikhar Maheswari and Karan Singh, "Hardware Implementation of an Eco-friendly Electronic Voting Machine" Indian Journal of Science and Technology, vol 8, issue 17, IPL088, August 2015.RM0041 Reference manual,

[22] Gaurav Verma, Oorja M Srivastava, Sushant Shekhar, Shikhar Maheswari, Sukhbani Kaur Virdi, "Low Power \& High Performance Implementation of Multiplier Architectures" in Proceedings of IEEE International Conference on "Computing for Sustainable Global Development", pp. 1989 - 1992, March 1 3, 2016.

[23] Gaurav Verma, Swati Gautam, Chetan Arora, Priyank Sharma, "Smart Cafe System Implementation" in Proceedings of IEEE International Conference on "Computing for Sustainable Global Development", pp. 2001 - 2003, March 1-3, 2016.

[24] Madhu Jain, Gaurav Verma, Himanshu Verma, "Smart Home System based on Internet on Things" in Proceedings of IEEE International Conference on "Computing for Sustainable Global Development", pp. 2073 - 2075, March 1 -3, 2016.

[25] Document Number: 37217, "LCD-016M002B", 2012.

[26] SIM300_HD_V1.06, "SIM300 hardware Specification”, 2007.

[27] Datasheet, "EM-18 RFID Reader".

[28] 5092D-SEEPR-4, "Two-wire Automotive Temperature Serial EEPROM", 2007.

[29] "ULN2001A-ULN2002A-ULN2003A-ULN2004A", 2002.

[30] 006-03 / 20130201 / ec211_sd, "Electromagnetic Buzzers", 2013.

[31] Rev. 3, "SA630-Single-Pole Double-Throw (SPDT) switch", 2014. 